\title{
EVALUATION OF THE READABILITY OF INFORMED CONSENT FORMS USED FOR EMERGENCY PROCEDURES
}

\author{
Leyla Ozturk Sonmez ${ }^{1,2}$, Mehmet Giray Sonmez ${ }^{3}$, Mustafa Kurşat Ayranci', Mehmet Gul ${ }^{1}$ \\ 'Department of Emergency Medicine, Meram Medical Faculty, Necmettin Erbakan University, Konya, Turkey \\ ${ }^{2}$ Department of Physiology, Selcuklu Medical School, Selcuk University, Konya, Turkey \\ ${ }^{3}$ Department of Urology, Meram Medical Faculty, Necmettin Erbakan University, Konya, Turkey
}

\begin{abstract}
INTRODUCTION: The aim of the study was to evaluate the readability levels of informed consent forms used for patient consent before emergency procedures applied in emergency service in Necmettin Erbakan University Meram Medical Faculty Emergency Service Clinic through readability formula.
\end{abstract}

METHOD: Fifteen informed patient consent forms used for emergency medical applications in Necmettin Erbakan University Meram Medical Faculty Emergency Medicine Department were evaluated. Information text available on the forms was transferred into Microsoft Word program. Average word number, syllable number and words with syllable number of four and above were calculated. Ateşman and Bezirci-Yılmaz formulas defined for determining the readability level of Turkish texts and Gunning fog, Flesch kincaid formulas measuring the general readability level were used for calculating the readability level of consent forms.

RESULTS: Readability levels of all consent forms were detected at average difficulty level according to Ateşman formula, very difficult according to Flesch-Kincaid formula, difficult according to Gunning fog formula and at high school level according to Bezirci-Yılmaz.

CONCLUSIONS: In this study, the readability level of emergency intervention consent forms used in the clinic was detected as hard and required high school or higher education level. The conclusion is that attention should be paid to this subject which is both medically and legally binding for the doctors and verbal and visual support should be provided for informing the patients in addition to consent forms.

KEY WORDS: emergency medicine, informed consent forms, readability, understandability

Disaster Emerg Med J 2018; 3(2): 51-55

\section{INTRODUCTION}

Informed consent is an important aspect of ethical medical practice. In legal terms, making an intervention without informed consent may mean negligence or malpractice and may cause a legal action, maltreatment and even attack against the doctor. Informed consent leads the way on the risks and advantages of all interventions and provides the voluntary consent of the patients in order to be able to continue the procedure. Informed consent form (ICF) through which the patients can completely understand the procedure to be applied can be called as ideal informed consent [1-3]. Presenting some quantitative data on texts, readability provides information on whether the text is easily understandable by the reader at a certain level through the 
characteristics of the syllables, words and sentences in that language. Factors influencing readability are the word length, word frequency, multi syllable number, sentence length, ambiguous word number and syllable number. The readability of the sentence decreases as the number of words in a sentence increase [4]. There are many formulas developed for readability analysis [5-8].

The aim of the study was to evaluate the readability levels of informed consent forms used for patient consent before emergency procedures applied in emergency service in Necmettin Erbakan University Meram Medical Faculty Emergency Service Clinic through readability formula.

\section{METHOD}

Fifteen ICFs used for emergency procedures in Necmettin Erbakan University Meram Medical Faculty, Emergency Medicine Department were evaluated. Information text available in these consent forms was copied and transferred to Microsoft Word (Microsoft, Redmond, WA) program and was calculated manually with Microsoft Excel (Microsoft, Redmond, WA) program. Average word number, syllable number and words with syllable number of four and above were calculated. Ateşman [5] and Bezirci-Yılmaz [6] formulas defined for determining the readability level of Turkish texts and Gunning fog [7], Flesch-Kincaid [8] formulas measuring the general readability level were used for calculating the readability level of consent forms.

\section{ATEŞMAN READABILITY FORMULA [5]}

It is a formula based on the length of word and sentence.

Readability Score is formulized as 198.825 $40.175 \times$ [total syllables/total words] $-2.610 \times$ [total words/total sentences]. It is understood that the readability level of a text is considered easier when it comes closer to 100 and harder when it comes closer to 0 according to Ateşman formula.

\section{BEZIRCI-YILMAZ READABILITY FORIULA [6]}

It was developed based on the sentence length and syllable number in words, characteristics in different formulas developed until today and the statistical characteristics of Turkish language. According to this formula, the readability difficulty of the texts increases when the sentences in the texts are longer. Similarly, the increase of the syllable number in the words makes the readability of that word and the sentences harder most of the time.

\section{AWN: Average word number}

S3:Number of words with an average of three syllables

S4:Number of words with an average of four syllables

S5:Number of words with an average of five syllables

S6:Number of words with an average of six or more syllables

$\sqrt{(\mathrm{AWNx}[(\mathrm{S} 3 \times 0.84)+(\mathrm{S} 4 \times 1.5)+(\mathrm{S} 5 \times 3.5)+(\mathrm{S} 6 \times 6.26 .25)])}$

The result acquired from this formula explains which class level a text addresses to according to the education system in Turkey. The education system shows elementary school education level for classes 1-8, secondary [high] school education for classes 9-12, bachelor's degree for classes 12-16 and academic education level for classes 16 and above.

\section{FLESCH-KINCAID FORMULA [7]}

The length of the words and sentences is determined.

Readability $=[0.39 \times$ sentencelength $]+[1.18 \times$ word length] -15.59

Word length = syllable number/word number Sentence length $=$ word number/sentence number.

Syllable number is divided by the word number for the word length and word number is divided by sentence number for sentence length. The text is evaluated as easy when the syllable number of each word is closer to 1 and as difficult when the syllable number rises up to 10 . The same operation is valid for the sentence. The text is evaluated as easy when the word number decreases to 1 and as difficult when it is more than 10 .

\section{GUNNING FOG INDEX FORMULA [8]}

There are two important aspects in Gunning's formula. These are words containing three or more syllables and the average number of words used in sentences. Fog Index $=0.4 \times$ (word rate with three syllables + average number of words)

Word rate with three syllables $=$ (number of words with three or more syllables/remaining number of words) $\times 100$ 
Average number of words $=$ word number/sentence number

It is an easy text if the result is between 8 and 10 and a difficult text above 11 . The readability intervals of the readability formulas used in the study are available in Table 1.

\section{RESULTS}

Fifteen ICFs used for emergency tube thoracostomy, endotracheal intubation, blood products transfusion, cardioversion and defibrillation, intramuscular injection, closed reduction of fractures and dislocations, small surgical interventions, lumbar puncture, parasynthesis, peritoneal lavage, fibrinolysis, central venous catheterisation, sedation, toracentesis, trachestomy. The most difficult to read is the endotracheal intubation ICF while the easiest to read is intramuscular injection ICF. Readability levels of all consent forms were detected at average difficulty level according to Ateşman formula, very difficult according to Flesch-Kincaid formula, difficult according to Gunning fog formula and at high school level according to Bezirci-Yılmaz. Numerical values for consent forms are available in Table 2.

\section{DISCUSSION}

The increasing tendency of health insurance costs and malpractice cases for especially the surgeons and doctors making invasive intervention makes the readability and understandability of informed consent forms more important $[9,10]$.

According to the studies made, patients can keep nearly $20 \%$ of the verbal information in their minds and maybe due to worry, pain, fear of unknown, time restrictions and lack of medical information, ratio of keeping information in mind rises nearly up to $50 \%$ when used together with written material. Thus taking informed consent forms before medical intervention is extremely important [11].

So it was concluded that there was a relation between education and understanding levels in general according to the studies made. Stating the target education level for a text provides a certain rate of information on its understandability. Consent

\begin{tabular}{|l|l|l|}
\hline \multicolumn{1}{|c|}{ Aableşman value 1 Readability intervals of the readability formulas used in the study } \\
\hline $90-100$ & \multicolumn{1}{|c|}{ Readability interval } \\
\hline $70-89$ & Very Easy & \\
\hline $50-69$ & Easy & \\
\hline $30-49$ & Average difficulty & \\
\hline $1-29$ & Difficult & \\
\hline \multicolumn{1}{|c|}{ Bezirci-YlImaz value } & Very difficult & \\
\hline $1-8$ & \multicolumn{1}{|c|}{ Readability Interval According to education level } & \\
\hline $9-12$ & Elementary school & \\
\hline $12-16$ & High school & \\
\hline$>16$ & Bachelor's degree & \\
\hline \multicolumn{1}{|c|}{ Gunning fog index value } & Academic & \\
\hline $8-10$ & & Readability interval \\
\hline$>11$ & Easy & \\
\hline \multicolumn{1}{|c|}{ Flesch-Kincaid grade level } & Difficult & \\
\hline 5 & & Numeric level of the text \\
\hline 6 & $90-100$ & Readability interval \\
\hline 7 & $80-90$ & Very easy \\
\hline $8-9$ & $70-80$ & Easy \\
\hline $10-11$ & $60-70$ & Quite easy \\
\hline $13-16$ & $50-60$ & Standard \\
\hline Adults & $30-50$ & Rather difficult \\
\hline & $0-30$ & Difficult \\
\hline & & Very difficult \\
\hline
\end{tabular}




\begin{tabular}{|l|c|}
\multicolumn{1}{|c|}{\begin{tabular}{l} 
Table 2. Numerical values of informed consent forms $(\mathbf{n}=\mathbf{1 5})$ \\
\hline \multicolumn{1}{|c|}{ Parameters }
\end{tabular}} \\
\hline Sentence number & Mean \pm Standard deviation \\
\hline Word number & $56.5 \pm 5.8$ \\
\hline Letter number & $3753 \pm 456.4$ \\
\hline Character number & $4862 \pm 668$ \\
\hline Syllables number & $1612 \pm 194.5$ \\
\hline Words with an average syllable number of four and above & $138.9 \pm 32.8$ \\
\hline Flesch-Kincaid & $20.3 \pm 3.18$ \\
\hline Gunning fog & $13.6 \pm 1.8$ \\
\hline Ateşman & $62.7 \pm 9.8$ \\
\hline Bezirci-Yllmaz & $10 \pm 1.12$ \\
\hline
\end{tabular}

forms for urgent or elective interventions should be understandable by the patient population at every education level.

As the average readability level of adults in USA is at $8^{\text {th }}$ grade level, National Institutes of Health $(\mathrm{NIH})$ and the American Medical Association [AMA] suggest that the readability of patient materials should be at $\leq 6^{\text {th }}$ grade reading level [12-14]. Even though the education level of the individual is high, it may cause misunderstanding for an individual not used to the medical literature. Thus consent forms should not contain medical terms as much as possible [4].

Readability levels of ICFs were measured in different countries for different medical branches before. Mariscal-Crespo et al. ICFs used in public hospitals were analyzed globally in Spain and it was shown that $62.4 \%$ had "somewhat difficult", $23.4 \%$ had "normal" and $13.4 \%$ had "very difficult" readability [14]. ICF readability values among the branches were compared in another study and it was reported that urology ICFs were at "very and somewhat difficult" interval [15]. In a study made in USA, it was reported that invasive operation ICFs were written at an average of $15^{\text {th }}$ grade level [i.e., $3^{\text {rd }}$ year of college] [16].

Gargoum and Keeffe evaluated the information forms used for endoscopic interventions in Ireland and reported that only $62 \%$ of the forms were easy to ready and $57 \%$ were at the reading level for 13-15 years of age [17].

While the average education level of the whole population over 15 years of age is reported as 7.18 years in Turkey according to 2010 data, average education level of only the females over 15 years of age is reported as 6.33 years [18]. Also according to the research made in 2014, it was detected that
$2 / 3$ of the society in Turkey has an inadequate level of health literacy [19].

In previous studies, it was reported that these forms were made easier with marked texts and diagrams so that ICFs could be understood and remembered more easily and these video supported forms were more understandable and easier to remember $[3,20]$.

Making readability level of ICFs easier and enriching them by visual information such as videos and diagrams would increase ratios for understanding the procedure and remembering its possible risks. In addition to an easier operative phase for both the patient and the doctor, this condition would also make the management of cases, which may occur due to the possible post-procedure complications, easier.

\section{CONCLUSIONS}

In this study, the readability level of emergency procedure consent forms used in the clinic was detected as hard and required high school or higher education level. It is concluded that attention should be paid to this subject which is both medically and legally binding for the doctors and verbal and visual support should be provided for informing the patients in addition to consent forms. Presentation of clear, understandable proof-based information with a suitable reading level in informed patient consent texts would contribute to improving the communication in medical intervention phase between the doctor and the patients. Associations and health institutions active in this field should cooperate to be able to develop new forms in line with the suggested strategies for the revision of the ICFs. 
Conflict of interest: The authors declare that they have no conflicts of interests. None of the authors involved in this study have any financial relationship.

Source of support: No sources of financial and material support to be declared.

Name of the department and institution in which the work was done: Department of Emergency Medicine, Meram Medical Faculty, Necmettin Erbakan University, Konya, Turkey.

\section{REFERENCES}

1. Sonmez M, Kozanhan B, Ozkent M, et al. The evaluation of the readability of informed consent forms used for urology: Is there a difference between open, endoscopic and laparoscopic surgery? Turkish Journal of Surgery. 2017, doi: 10.5152/turkjsurg.2017.3973.

2. Hilgart MM, Ritterband LM, Thorndike FP, et al. A behavior change model for internet interventions. Ann Behav Med. 2009; 38(1): 18-27, doi: 10.1007/s12160-009-9133-4, indexed in Pubmed: 19802647.

3. Borello A, Ferrarese A, Passera $R$, et al. Use of a simplified consent form to facilitate patient understanding of informed consent for laparoscopic cholecystectomy. Open Med (Wars). 2016; 11(1): 564-573, doi: 10.1515/med-2016-0092, indexed in Pubmed: 28352847.

4. Boztaş N, Özbilgin Ş, Öçmen E, et al. Evaluating the readibility of informed consent forms available before anaesthesia: a comparative study. Turk J Anaesthesiol Reanim. 2014; 42(3): 140-144, doi: 10.5152/TJAR.2014.94547, indexed in Pubmed: 27366408.

5. Ateşman E. Measuring readability in Turkish. A.U. Tömer Language Journal. 1997; 58: 171-174.

6. Bezirci $B$, Yllmaz AE. A software library for measurement of readability of texts and a new readability metric for turkish. DEÜ FMD. 2010; 12(3): 49-62.

7. Flesch R. A new readability yardstick. J Appl Psychol. 1948; 32(3): 221-233, indexed in Pubmed: 18867058.

8. Gunning R. The Technique of Clear Writing. McGraw-Hill International Book Co, New York 1952.

9. Mello MM, Studdert DM, DesRoches CM, et al. Effects of a malpractice crisis on specialist supply and patient access to care. Ann Surg. 2005; 242(5): 621-628, indexed in Pubmed: 16244532.
10. Paasche-Orlow MK, Taylor HA, Brancati FL. Readability standards for informed-consent forms as compared with actual readability. N Engl J Med. 2003; 348(8): 721-726, doi: 10.1056/NEJMsa021212, indexed in Pubmed: 12594317.

11. Sanghvi S, Cherla DV, Shukla PA, et al. Readability assessment of internet-based patient education materials related to facial fractures. Laryngoscope. 2012; 122(9): 1943-1948, doi: 10.1002/lary.23424, indexed in Pubmed: 22833340.

12. Eltorai AEM, Sharma P, Wang J, et al. Most American Academy of Orthopaedic Surgeons' online patient education material exceeds average patient reading level. Clin Orthop Relat Res. 2015; 473(4): 1181-1186, doi: 10.1007/s11999-014-4071-2, indexed in Pubmed: 25475715.

13. Eltorai AEM, Han A, Truntzer J, et al. Readability of patient education materials on the American Orthopaedic Society for Sports Medicine website. Phys Sportsmed. 2014; 42(4): 125-130, doi: 10.3810/ psm.2014.11.2099, indexed in Pubmed: 25419896.

14. Eltorai AEM, Ghanian S, Adams CA, et al. Readability of patient education materials on the american association for surgery of trauma website. Arch Trauma Res. 2014; 3(2): e18161, doi: 10.5812/ atr.18161, indexed in Pubmed: 25147778.

15. San Norberto EM, Gómez-Alonso D, Trigueros JM, et al. [Readability of surgical informed consent in Spain]. Cir Esp. 2014; 92(3): 201-207, doi: 10.1016/j.ciresp.2013.02.027, indexed in Pubmed: 24060163.

16. Eltorai AEM, Naqvi SS, Ghanian $S$, et al. Readability of Invasive Procedure Consent Forms. Clin Transl Sci. 2015; 8(6): 830-833, doi: 10.1111/cts.12364, indexed in Pubmed: 26678039.

17. Gargoum FS, O'Keeffe ST. Readability and content of patient information leaflets for endoscopic procedures. Ir J Med Sci. 2014; 183(3): 429-432, doi: 10.1007/s11845-013-1033-8, indexed in Pubmed: 24174395.

18. Barro R, Lee JW. Educational Attainment Dataset. Available at: www. barrolee.com.

19. Tanrı̈ver MD, Yıldırım HH, Ready FND, et al. Turkey Health Literacy Survey. Available at: www.sagliksen.org.tr/cdn/uploads/gallery/ pdf/8dcec50aa18c21cdaf86a2b33001a409.pdf.

20. Shukla AN, Daly MK, Legutko P. Informed consent for cataract surgery: patient understanding of verbal, written, and videotaped information. J Cataract Refract Surg. 2012; 38(1): 80-84, doi: 10.1016/j. jcrs.2011.07.030, indexed in Pubmed: 22062774. 